\title{
Advanced malignancies treated with a combination of the VEGF inhibitor bevacizumab, anti-EGFR antibody cetuximab, and the mTOR inhibitor temsirolimus
}

\author{
Xiaochun Liu ${ }^{1}$, Susan Kambrick ${ }^{1}$, Siqing Fu ${ }^{1}$, Aung Naing ${ }^{1}$, Vivek Subbiah ${ }^{1}$, George \\ R. Blumenschein ${ }^{2}$, Bonnie S. Glisson ${ }^{2}$, Merrill S. Kies ${ }^{2}$, Apostolia M. Tsimberidou ${ }^{1}$, \\ Jennifer J. Wheler ${ }^{1}$, Ralph G. Zinner ${ }^{1}$, David S. Hong ${ }^{1}$, Razelle Kurzrock ${ }^{3}$ and Sarina \\ A. Piha-Paul ${ }^{1}$ \\ ${ }^{1}$ Department of Investigational Cancer Therapeutics, University of Texas, MD Anderson Cancer Center, Houston, Texas, USA \\ ${ }^{2}$ Department of Thoracic/Head \& Neck Medical Oncology, University of Texas, MD Anderson Cancer Center, Houston, TX, USA \\ ${ }^{3}$ Division of Hematology and Oncology, University of California San Diego, Moores Cancer Center, San Diego, CA, USA \\ Correspondence to: Sarina A. Piha-Paul, email: spihapau@mdanderson.org
}

Keywords: solid tumors, bevacizumab, cetuximab, temsirolimus

Received: August 20,2015 Accepted: February 05, 2016

Published: February 24, 2016

\section{ABSTRACT}

BACKGROUND: Bevacizumab and temsirolimus are active agents in advanced solid tumors. Temsirolimus inhibits $\mathrm{mTOR}$ in the PI3 kinase/AKT/mTOR pathway as well as CYP2A, which may be a resistance mechanism for cetuximab. In addition, temsirolimus attenuates upregulation of HIF-1a levels, which may be a resistance mechanism for bevacizumab.

RESULTS: The median age of patients was 60 years (range, 23-80 years). The median number of prior systemic therapies was 3 (range, 1-6). The maximum tolerated dose (MTD) was determined to be bevacizumab $10 \mathrm{mg} / \mathrm{kg}$ biweekly, temsirolimus $5 \mathrm{mg}$ weekly and cetuximab $100 / 75 \mathrm{mg} / \mathrm{m} 2$ weekly. Grade 3 or 4 toxicities were seen in $52 \%$ of patients with the highest prevalence being hyperglycemia $(14 \%)$ and hypophosphatemia (14\%). Eighteen of the 21 patients were evaluable for response. Three patients were taken off the study before restaging for toxicities. Partial response (PR) was observed in $2 / 18$ patients $(11 \%)$ and stable disease (SD) lasting $\geq 6$ months was observed in $4 / 18$ patients $(22 \%)$ (total $=6 / 18(33 \%)$ ). In 8 evaluable patients with squamous cell carcinoma of the head and neck (HNSCC) there were partial responses in $2 / 8(25 \%)$ patients and SD $\geq 6$ months in $1 / 8(13 \%)$ patients (total $=3 / 8,(38 \%)$ ).

PATIENTS AND METHODS: We analyzed safety and responses in 21 patients with advanced solid tumors treated with bevacizumab, cetuximab, and temsirolimus.

CONCLUSION: The combination of bevacizumab, cetuximab, and temsirolimus showed activity in HNSCC; however, there were numerous toxicities reported, which will require careful management for future clinical development.

\section{INTRODUCTION}

Epidermal growth factor receptor (EGFR), vascular endothelial growth factor (VEGF), and mammalian target of rapamycin (mTOR) are important targets in a wide array of malignancies [1]. Cetuximab is a monoclonal antibody that inhibits EGFR signaling, resulting in inhibition of cell growth, induction of apoptosis, and decreased matrix metalloproteinase and VEGF production [2]. It has been approved by the US Food and Drug Administration (FDA) to treat colorectal cancer as well as head and neck cancer [3]. Bevacizumab is a monoclonal antibody specific for the VEGF family of proteins and receptors that are important in tumor angiogenesis and fundamental for tumor growth and metastasis [4-8]. Bevacizumab has been approved by the FDA to treat metastatic cancers including colorectal cancer, non-small cell lung cancer, glioblastoma, cervical cancer, and renal cell carcinoma [9]. Temsirolimus is an mTOR inhibitor that inhibits the phosphoinositide 3-kinase (PI3K)/ Protein kinase B (AKT)/mTOR pathway, which 
is involved in protein synthesis, cellular proliferation, and tumor angiogenesis $[10,11]$. Temsirolimus has been approved by the FDA to treat renal cell carcinoma [12].

A given tumor is unlikely to be dependent upon only one receptor or signaling pathway for its growth and survival. This is due to the significant level of compensatory cross talk among receptors within a signaling network as well as heterologous receptor systems $[13,14]$. Therefore, combining drugs inhibiting different signaling pathways is currently an important strategy to achieve synergy or overcome resistance.

The synergy between the VEGF and EGFR pathways lies in their close relationship and sharing common downstream signaling pathways [15]. Activation of EGFR signaling in tumor cells stimulates the production of VEGF, which then acts in a paracrine fashion on surrounding endothelial cells to stimulate their proliferation and migration $[16,17]$. Combinations of $\operatorname{VEGF(R)}$ and EGFR inhibitors have shown synergy in antitumor activities in lung cancer and colorectal cancer in preclinical studies [18-20]. In a phase II clinical study of 46 patients with squamous cell carcinoma of the head and neck (HNSCC), bevacizumab in combination with cetuximab achieved an objective response rate of $16 \%$ and a disease control rate of $73 \%$ [21, 22]. The median progression-free survival and overall survival were 2.8 and 7.5 months, respectively.

One mechanism of tumor resistance to antiangiogenic therapy (e.g. bevacizumab) is upregulation of hypoxia-inducible factor $1 \alpha$ (HIF-1 $\alpha$ ), which mediates adaptive responses to hypoxic conditions [6, 23-30]. HIF$1 \alpha$ inhibition in combination with antiangiogenic therapy is a promising strategy for targeting tumor resistance [27, 31-34]. Temsirolimus has been shown to inhibit the activity of mTOR and has resulted in reduced levels of HIF-1 $\alpha$, HIF-2 $\alpha$ and VEGF [30]. The discovery of the HIF- $1 \alpha$ inhibition properties of temsirolimus makes it an ideal candidate for combination with bevacizumab. In a phase I clinical study of 41 heavily-pretreated patients with gynecological malignancies, $37 \%$ achieved disease control [21].

It has been suggested that downstream PI3KAKT-mTOR hyperactivation may represent an acquired mechanism of resistance to EGFR inhibition that can be overcome by combination therapy. In addition, temsirolimus enhances anti-cancer efficacy of cetuximab through the inhibition of protein phosphatase $2 \mathrm{~A}(\mathrm{CYP} 2 \mathrm{~A})$ in preclinical models of colorectal cancer [35]. Temsirolimus added to cetuximab in cetuximab-refractory head and neck cancer patients induced responses in 16.7\% of subjects [36]. Therefore, adding temsirolimus to the combination may abrogate resistance to both bevacizumab and cetuximab.

Taken together, there are several compelling rationales for combining bevacizumab, temsirolimus, and cetuximab in treating advanced malignancies: i) bevacizumab and cetuximab may be synergistic; ii) temsirolimus inhibits mTOR and the PI3 kinase/AKT/ mTOR pathway as well as CYP2A, which may be a resistance mechanism for cetuximab; iii) temsirolimus attenuates upregulation of HIF-1 $\alpha$ levels, which may be a resistance mechanism for bevacizumab; and iv) the three agents have non-overlapping toxicities. Here we report our experience treating patients with advanced malignancies with this combination therapy.

\section{RESULTS}

\section{Demographic and clinical characteristics}

Twenty-one patients with advanced, metastatic malignancies were enrolled between March 2012 and February 2014. Demographic and clinical characteristics are summarized in Table 1. The median age of patients was 60 years (range, 23-80 years). The median number of prior systemic therapies was 3 (range, 1-6). Before enrollment onto the trial, three patients had received prior mTOR inhibitors ( 2 patients had received temsirolimus and 1 patient had received everolimus), four patients had received prior bevacizumab, and seven patients had received prior cetuximab. The most common cancer type was HNSCC followed by melanoma. All patients had experienced disease progression on their prior therapy. The median number of cycles (cycle $=28$ days) completed for all patients was 2 (range, 1-10). Ten patients (48\%) received more than 2 cycles. For patients with SD or better, the median number of cycles completed was 4 (range, 1-10).

\section{Toxicity assessment}

Patient enrollment proceeded in accordance with the planned $3+3$ study design (Table 2 ). Three patients were enrolled in dose level 1 . The toxicities seen in dose level 1 included grade 3 neutropenia along with grade 1-2 anemia, dermatitis, epistaxis, fatigue, hypercholesterolemia, hyperglycemia, hyperkalemia, hypertriglyceridemia, hypokalema, hypophosphatemia, elevated AST/ALT, renal insufficiency, mucositis/glossitis, nausea, vomiting, proteinuria, fistula, hypomagnesemia and pneumonitis (Table 3). No DLTs were observed in dose level 1. Three patients were then enrolled in dose level 2. No DLTs were obtained in dose level 2. At dose level 3, our first patient experienced two DLTs (grade 3 mucositis and grade 3 fatigue) and the second patient enrolled experienced a DLT (grade 3 headache) as well. Therefore, the enrollment for dose level 3 was discontinued per protocol. We enrolled 3 additional patients to confirm that dose level 2 was safe and after verifying tolerability, enrolled 10 additional patients to further evaluate toxicity and preliminary 
Table 1: Baseline demographics and clinical characteristics $(\mathrm{N}=21)$

\begin{tabular}{|c|c|}
\hline Patient Characteristic & Total $(\%)$ \\
\hline \multicolumn{2}{|l|}{ Age, years } \\
\hline Median (Range) & $60(23-80)$ \\
\hline \multicolumn{2}{|l|}{ Gender } \\
\hline Male & $13(62 \%)$ \\
\hline Female & $8(38 \%)$ \\
\hline \multicolumn{2}{|l|}{ ECOG performance status* } \\
\hline 0 & $4(19 \%)$ \\
\hline 1 & $17(81 \%)$ \\
\hline \multicolumn{2}{|l|}{ Number of prior systemic therapies } \\
\hline Median (Range) & $3(1-6)$ \\
\hline Number of prior temsirolimus & $2(10 \%)$ \\
\hline Number of prior bevacizumab & $4(19 \%)$ \\
\hline Number of prior cetuximab & $7(33 \%)$ \\
\hline \multicolumn{2}{|l|}{ Tumor type } \\
\hline Colorectal & 1 \\
\hline Squamous cell carcinoma head \& neck & $9(43 \%)$ \\
\hline Melanoma & $2(10 \%)$ \\
\hline Chondrosarcoma & 1 \\
\hline Cholangiocarcinoma & 1 \\
\hline Mesothelioma & 1 \\
\hline Cervical adenoma & 1 \\
\hline Adenocarcinoma of tongue & 1 \\
\hline Adenocarcinoma of Gastroesophageal Junction & 1 \\
\hline Gastric adenocarcinoma & 1 \\
\hline Adnexal carcinoma & 1 \\
\hline Urethral carcinoma & 1 \\
\hline
\end{tabular}

*ECOG $=$ Eastern Cooperative Oncology Group.

Table 2: Dose-Escalation Schedule (28-day cycle), Grade 3/4 Toxicities* and Response

\begin{tabular}{|c|c|c|c|c|c|c|}
\hline $\begin{array}{l}\text { Dose } \\
\text { Level }\end{array}$ & $\mathbf{N}$ & $\begin{array}{l}\text { Temsirolimus } \\
\text { IV on Days } 1 \text {, } \\
8,15,22\end{array}$ & $\begin{array}{l}\text { Bevacizumab IV } \\
\text { on Days } 1,15\end{array}$ & $\begin{array}{l}\text { Cetuximab IV } \\
\text { on Days 1, 8, } \\
15,22\end{array}$ & $\begin{array}{l}\mathrm{SD} \geq 6 \text { months or } \\
\text { PR/Total treated }\end{array}$ & Grade (G) 3/4 Toxicity (N)* \\
\hline 1 & 3 & $5 \mathrm{mg}$ & $5 \mathrm{mg} / \mathrm{kg}$ & $100 / 75 \mathrm{mg} / \mathrm{m}^{2}$ & $1 / 3$ & G3/4 Neutropenia (1) \\
\hline 2 & 16 & $5 \mathrm{mg}$ & $10 \mathrm{mg} / \mathrm{kg}$ & $100 / 75 \mathrm{mg} / \mathrm{m}^{2}$ & $5 / 16$ & $\begin{array}{l}\text { G3 Hypophosphatemia (1) } \\
\text { G3 Elevated Aspartate } \\
\text { Aminotransferase (1) } \Delta \\
\text { G3 Hyperglycemia (3) } \\
\text { G3 Hypokalemia (1) } \\
\text { G3 Anemia (1) } \\
\text { G3 Hyperkalemia (1) } \\
\text { G3 Infusion reaction }(1)^{\Delta} \\
\text { G3 Vomiting (1) } \\
\text { G4 Stomach leak/perforation }(1)^{\Delta}\end{array}$ \\
\hline 3 & 2 & $12.5 \mathrm{mg}$ & $2.5 \mathrm{mg} / \mathrm{kg}$ & $100 / 75 \mathrm{mg} / \mathrm{m}^{2}$ & $0 / 2$ & $\begin{array}{l}\text { G3 Headache }(1) \Delta \\
\text { G3 Hypophosphatemia (2) } \\
\text { G3 Mucositis }(1)^{\Delta} \\
\text { G3 Fatigue }(1)^{\Delta}\end{array}$ \\
\hline
\end{tabular}

*Adverse events deemed at least possibly related to treatment were graded based on the Common Terminology Criteria for Adverse Events, version 3.0 (CTCAEv3.0).

${ }^{\Delta}$ was defined as a dose-limiting toxicity.

Abbreviations: $\mathrm{N}$, number of patients. 
anti-tumor efficacy as an MTD expansion cohort. The toxicities based on a total of 16 patients treated at dose level 2 were: grade 4 stomach leak/perforation; grade 3 hypophosphatemia, elevated AST, hyperglycemia, hypoor hyperkalemia, anemia, infusion reaction and vomiting; and, grade 1-2 anemia, dermatitis, epistaxis, fatigue, hypercholesterolemia, hyperglycemia, hyperkalemia, hypertriglyceridemia, hypokalema, hypophosphatemia, elevated AST/ALT, renal insufficiency, infection, neutropenia/leukopenia, mucositis/glossitis, nail discoloration, nausea, proteinuria, dyspnea with exertion, stomatitis, thrombocytopenia, abdominal pain, anorexia, diarrhea, dysuria, fever, headache, hypertension and hyperbilirubinemia (Table 3). Among these, grade 4 stomach leak/perforation, grade 3 elevated AST, and grade 3 infusion related reaction are considered DLTs. However, it is important to note that these 3 DLTs occurring in 3 separate patients did not meet the criteria for MTD as the total number of DLTs occurred in less than $33 \%$ of patients (3/16 patients or $19 \%)$. Per protocol, dose level 2 (bevacizumab $10 \mathrm{mg} / \mathrm{kg}$ biweekly, temsirolimus $5 \mathrm{mg}$ weekly and cetuximab 100/75 mg/m2 weekly) was defined as the maximum tolerated dose (MTD).

All 21 patients with advanced malignancy experienced at least one adverse event that was possibly related to the drug. These events were mostly grade 1 or 2 and reversible. In fact, 10 patients (48\%) experienced toxicity no greater than grade 2 . Grade 3 or 4 toxicities were as follows: hyperglycemia (14\%), hypophosphatemia $(14 \%)$, headache $(5 \%)$, hyperkalemia $(5 \%)$, hypokalemia $(5 \%)$, fatigue $(5 \%)$, elevated aspartate aminotransferase (AST) (5\%), decreased absolute neutrophil count/ leucopenia $(5 \%)$, mucositis $(5 \%)$, anemia $(5 \%)$, infusion reaction (5\%), vomiting (5\%), and stomach leak/ perforation (5\%) (Table 3). Among the toxicities, six DLTs were observed in five patients at two dose levels: grade 3 elevated AST, grade 3 infusion reaction, and grade 4 stomach leak/rupture (patient had gastric antral mass) in three separate patients at dose level 2 (bevacizumab 10 $\mathrm{mg} / \mathrm{kg}$ and temsirolimus $5 \mathrm{mg}$, cetuximab 100/75 mg/ $\mathrm{m}^{2}$ weekly); grade 3 fatigue and grade 3 mucositis in one patient and grade 3 headache (not posterior reversible encephalopathy syndrome (PRES)) in another patient at dose level 3 (bevacizumab $2.5 \mathrm{mg} / \mathrm{kg}$ and temsirolimus $12.5 \mathrm{mg}$, cetuximab 100/75 $\mathrm{mg} / \mathrm{m}^{2}$ weekly) (Table $2)$. Three patients $(14 \%)$ came off study before the first restaging due to toxicities: grade 4 stomach leak/ rupture, grade 3 headache, and grade 3 infusion reaction, respectively. There were no thromboembolic events or cases of significant proteinuria. Of the 16 patients treated at the MTD, one patient $(6 \%)$ was dose-reduced for toxicities occurring during the first cycle. In this case, the cetuximab was dose reduced by $50 \%$ because of grade 3 elevated AST.

\section{Antitumor activity}

Of 21 total patients on the trial, 16/21 (76\%) patients had disease that was measurable by RECIST and reached restaging; $2 / 21$ (10\%) patients had clinical progression; and $3 / 21(14 \%)$ patients were taken off the study before restaging for toxicities. For the purposes of reporting, 18/21 (86\%) patients were considered evaluable for response. Figure 1 is a waterfall plot depicting best response of the 18 patients. Partial response (PR) was observed in $2 / 18$ patients (11\%); and stable disease (SD) lasting $\geq 6$ months was observed in $4 / 18$ patients $(22 \%)$ (total $=6 / 18(33 \%)$ with SD $\geq 6$ months/ PR). Details regarding these patients including dose level, duration of treatment, and best response by RECIST 1.0 are described in Table 4.

Of 8 patients with evaluable $\mathrm{HNSCC}, \mathrm{SD} \geq 6$ months/ PR was achieved in $3(38 \%)$ patients. These included two PRs (one patient with cancer arising from the base of the tongue with prior exposure to cetuximab (Figure 2) and one patient with cancer arising from the left tonsil with no prior exposure to cetuximab) and one SD for 10 months (in a patient with cancer arising from the oral tongue with prior exposure to cetuximab). Human papilloma virus (HPV) test was negative in the patient with HNSCC from the base of the tongue who achieved PR for 4 months. HPV testing was equivocal in the patient with HNSCC from the left tonsil who achieved PR for 7 months. Finally, for the HNSCC achieving SD for 10 months whose disease arose from the oral tongue, HPV testing was negative. The $1 / 1$ patient with adenocarcinoma of the tongue attained prolonged SD for 8 months. It was also observed that $1 / 2$ melanoma patients and $1 / 1$ chondrosarcoma patient achieved prolonged SD for 8 months and 10 months, respectively.

\section{Molecular analysis and association with response}

When archival cell blocks for patients were available, CLIA-certified testing was performed for $B R A F$, NRAS, KRAS, HRAS, PTEN, P53 and PIK3CA mutations along with evaluation for PTEN loss by IHC. Fourteen out of 21 patients $(67 \%)$ had known mutational status (Table 5). PIK3CA mutational status was positive in $1 / 14$ (7\%) patients and this patient had progressive disease. PTEN mutation was found in $2 / 14$ patients (14\%) tested; both patients were off study before restaging due to toxicities. Only one patient $(7 \%)$ had IHC testing and confirmed PTEN loss; this patient had $23 \%$ decrease of target lesions as the best response and eventually progressed after 3 cycles of treatment. Of all 14 patients with $R A S$ and $R A F$ mutational analysis, only one patient $(7 \%)$ was positive for $H R A S$ mutation. This patient had progressive disease. P53 is a predictor of response to bevacizumab [37]. In addition, Schwaederle et al. demonstrated that P53 mutations 
Table 3: Adverse events at any dose level.

\begin{tabular}{|c|c|c|c|c|c|c|c|c|}
\hline \multirow[t]{3}{*}{$\begin{array}{l}\text { Adverse Event of All } \\
\text { Grades }\end{array}$} & \multicolumn{8}{|c|}{$\begin{array}{l}\text { Dose Level of Temsirolimus (mg)/Bevacizumab (mg/kg)/Cetuximab LD/MD (mg/ } \\
\left.\mathrm{m}^{2}\right)\end{array}$} \\
\hline & \multicolumn{2}{|c|}{$\begin{array}{l}5 / 5 / 100 / 75 \\
(\mathrm{n}=3)\end{array}$} & \multicolumn{2}{|c|}{$\begin{array}{l}5 / 10 / 100 / 75 \\
(\mathrm{n}=16)\end{array}$} & \multicolumn{2}{|c|}{$\begin{array}{l}12.5 / 2.5 / 100 / 75 \\
(\mathrm{n}=2)\end{array}$} & \multicolumn{2}{|c|}{$\begin{array}{l}\text { Total } \\
(\mathrm{n}=21)\end{array}$} \\
\hline & G1-2 & G3-4 & G1-2 & G3-4 & G1-2 & G3-4 & G1-2 & G3-4 \\
\hline Abdominal Pain & 0 & 0 & 1 & 0 & 0 & 0 & 1 & 0 \\
\hline Anemia & 3 & 0 & 13 & 1 & 2 & 0 & 18 & 1 \\
\hline Anorexia & 0 & 0 & 2 & 0 & 2 & 0 & 4 & 0 \\
\hline Dermatitis & 1 & 0 & 10 & 0 & 1 & 0 & 12 & 0 \\
\hline Diarrhea & 0 & 0 & 1 & 0 & 0 & 0 & 1 & 0 \\
\hline Dysuria & 0 & 0 & 1 & 0 & 0 & 0 & 1 & 0 \\
\hline Epistaxis & 1 & 0 & 2 & 0 & 0 & 0 & 3 & 0 \\
\hline Fatigue & 2 & 0 & 8 & 0 & 1 & 1 & 11 & 1 \\
\hline Fever & 0 & 0 & 1 & 0 & 0 & 0 & 1 & 0 \\
\hline Headache & 0 & 0 & 4 & 0 & 1 & 1 & 5 & 1 \\
\hline Hypercholesterolemia & 2 & 0 & 9 & 0 & 0 & 0 & 11 & 0 \\
\hline Hyperglycemia & 3 & 0 & 8 & 3 & 1 & 0 & 12 & 3 \\
\hline Hyperkalemia & 1 & 0 & 2 & 1 & 2 & 0 & 5 & 1 \\
\hline Hypertension & 0 & 0 & 2 & 0 & 0 & 0 & 2 & 0 \\
\hline Hypertriglyceridemia & 3 & 0 & 11 & 0 & 1 & 0 & 15 & 0 \\
\hline Hypokalemia & 1 & 0 & 4 & 1 & 1 & 0 & 6 & 1 \\
\hline Hypophosphatemia & 1 & 0 & 3 & 1 & 0 & 2 & 4 & 3 \\
\hline Elevated AST & 3 & 0 & 8 & 1 & 0 & 0 & 11 & 1 \\
\hline Hyperbilirubinemia & 0 & 0 & 1 & 0 & 0 & 0 & 1 & 0 \\
\hline Renal Insufficiency & 1 & 0 & 3 & 0 & 0 & 0 & 4 & 0 \\
\hline Elevated ALT & 2 & 0 & 6 & 0 & 1 & 0 & 9 & 0 \\
\hline Infection (ear, orbit) & 1 & 0 & 3 & 0 & 0 & 0 & 4 & 0 \\
\hline $\begin{array}{l}\text { Leukopenia/ } \\
\text { Neutropenia }\end{array}$ & 0 & 1 & 5 & 0 & 1 & 0 & 6 & 1 \\
\hline Mucositis/Glossitis & 2 & 0 & 8 & 0 & 0 & 1 & 10 & 1 \\
\hline Nail Discoloration & 0 & 0 & 2 & 0 & 0 & 0 & 2 & 0 \\
\hline Nausea & 1 & 0 & 3 & 0 & 2 & 0 & 6 & 0 \\
\hline Proteinuria & 2 & 0 & 11 & 0 & 0 & 0 & 13 & 0 \\
\hline Dyspnea with Exertion & 0 & 0 & 1 & 0 & 0 & 0 & 1 & 0 \\
\hline Stomatitis & 0 & 0 & 2 & 0 & 0 & 0 & 2 & 0 \\
\hline Thrombocytopenia & 0 & 0 & 3 & 0 & 2 & 0 & 5 & 0 \\
\hline Fistula & 1 & 0 & 0 & 0 & 0 & 0 & 1 & 0 \\
\hline Hypomagnesemia & 1 & 0 & 0 & 0 & 0 & 0 & 1 & 0 \\
\hline Pneumonitis & 1 & 0 & 0 & 0 & 0 & 0 & 1 & 0 \\
\hline Vomiting & 1 & 0 & 0 & 1 & 2 & 0 & 3 & 1 \\
\hline Oral thrush & 0 & 0 & 0 & 0 & 1 & 0 & 1 & 0 \\
\hline Constipation & 0 & 0 & 0 & 0 & 1 & 0 & 1 & 0 \\
\hline Infusion Reaction & 0 & 0 & 0 & 1 & 0 & 0 & 0 & 1 \\
\hline Stomach leak/rupture & 0 & 0 & 0 & 1 & 0 & 0 & 0 & 1 \\
\hline
\end{tabular}

LD: loading dose; MD: maintenance dose. 
Table 4: Stable disease $\geq 6$ months or partial response (PR) by RECIST and characterization by patient.

\begin{tabular}{|c|c|c|c|c|c|c|c|c|c|c|}
\hline & Cancer Type & $\begin{array}{l}\text { Dose } \\
\text { Level }\end{array}$ & \begin{tabular}{|l|} 
Best \\
Response \\
by RECIST \\
1.0
\end{tabular} & $\begin{array}{l}\# \text { of Prior } \\
\text { Cytotoxic } \\
\text { Regimens }\end{array}$ & $\begin{array}{l}\text { Duration of } \\
\text { Treatment (Weeks) }\end{array}$ & $\begin{array}{l}\text { PTEN } \\
\text { mut* }\end{array}$ & $\begin{array}{l}\text { PIK3CA } \\
\text { mut }\end{array}$ & $\begin{array}{l}R A S \\
\text { mut }\end{array}$ & $\begin{array}{l}R A F \\
\text { mut }\end{array}$ & $\begin{array}{l}\text { P53 } \\
\text { mut }\end{array}$ \\
\hline $9 \zeta$ & HNSCC & 1 & $-29 \%$ & 2 & 40 & $\mathrm{~N}$ & $\mathrm{~N}$ & $\mathrm{~N}$ & $\mathrm{~N}$ & $\mathrm{~N}$ \\
\hline 35 & Chondrosarcoma & 2 & $-2 \%$ & 4 & 40 & $\mathrm{~N}$ & $\mathrm{~N}$ & $\mathrm{~N}$ & $\mathrm{~N}$ & $\mathrm{~N}$ \\
\hline $42^{\Delta}$ & $\begin{array}{l}\text { Adenocarcinoma } \\
\text { of the tongue }\end{array}$ & 2 & $-7 \%$ & 5 & 32 & $\mathrm{~N}$ & $\mathrm{~N}$ & $\mathrm{~N}$ & $\mathrm{~N}$ & $\mathrm{Y}$ \\
\hline $46^{\zeta}$ & HNSCC & 2 & $-54 \%$ & 2 & 16 & $\mathrm{~N}$ & $\mathrm{~N}$ & $\mathrm{~N}$ & $\mathrm{~N}$ & $\mathrm{~N}$ \\
\hline 48 & HNSCC & 2 & $-35 \%$ & 3 & 28 & $\mathrm{~N}$ & $\mathrm{~N}$ & $\mathrm{~N}$ & $\mathrm{~N}$ & $\mathrm{~N}$ \\
\hline 59 & Melanoma & 2 & $+3 \%$ & 3 & 32 & $\mathrm{~N}$ & $\mathrm{~N}$ & $\mathrm{~N}$ & $\mathrm{~N}$ & ND \\
\hline
\end{tabular}

Abbreviations: N, no mutation; Mut, mutation; ND, not done; HNSCC, squamous cell carcinoma of the head and neck; P, present.

*PTEN loss by immunohistochemistry was not performed.

${ }^{\Delta}$ indicates a patient with prior temsirolimus and bevacizumab treatment.

$\zeta$ indicates a patient with prior cetuximab treatment.

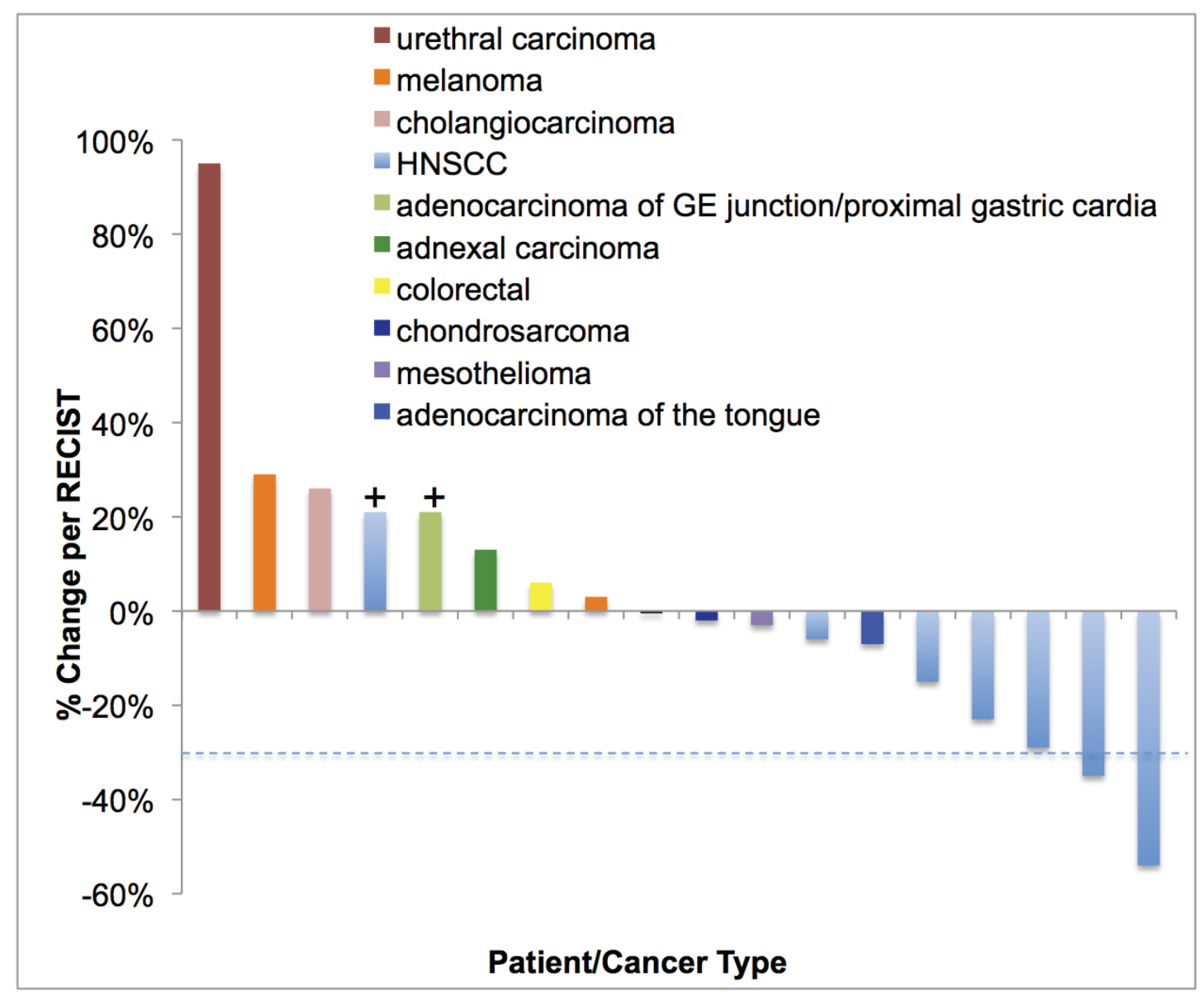

Figure 1: Waterfall plot depicting best RECIST response by patient. Individual patients/disease sites are represented by vertical bars on the X-axis. The best RECIST response (\%) is depicted on the Y-axis. Sixteen of the 21 patients were measurable by RECIST. Two patients were assigned a value of $+21 \%$ for clinical progression or new lesions $(+)$. Three patients are not included in this plot as they never reached restaging due to being taken off the study early in the first cycle for toxicity. Dotted line shows $30 \%$ response by RECIST. 
Table 5: Tumor molecular analysis

\begin{tabular}{|l|l|l|l|}
\hline Tumor Molecular Aberration & N/Total tested (\%) & Cancer Type & Best Response Comments \\
\hline PIK3CA (C378F) & $1 / 14(7 \%)$ & Cholangiocarcinoma & $26 \%$ increase \\
\hline PTEN (R173C) & $1 / 14(7 \%)$ & Cervical cancer & $\begin{array}{l}\text { NE; off study for grade 3 headache } \\
\text { after first bevacizumab infusion }\end{array}$ \\
\hline PTEN (R335*) & $1 / 14(7 \%)$ & HNSCC & $\begin{array}{l}\text { NE; off study for grade 3 infusion } \\
\text { reaction during first cetuximab } \\
\text { infusion }\end{array}$ \\
\hline PTEN loss & $1 / 14(7 \%)$ & HNSCC & $23 \%$ decrease \\
\hline HRAS (Q61R) & $1 / 14(7 \%)$ & Urethral carcinoma & $95 \%$ increase \\
\hline
\end{tabular}

Abbreviation: N, number of patients; NE, no response evaluation; HNSCC, squamous cell carcinoma of the head and neck; IHC, immunohistochemistry

correlate strongly with increased VEGF-A, the target of bevacizumab [38]. In our study, we had two patients with P53 aberration. The first patient had adenocarcinoma of gastroesophageal junction/proximal gastric cardia, which was positive for TP53 Y103*, a deletion/insertion in exon 4 of the TP53 gene, which is predicted to result in a stop codon with early termination of translation. This patient had progressive disease at cycle 1 day 21 . The second patient had adenocarcinoma of the tongue that was positive for TP53 R213*, which is a hotspot mutation. This patient had stable disease for 8 cycles.

\section{DISCUSSION}

This is the first study to evaluate the combination of bevacizumab, temsirolimus, and cetuximab in patients with advanced malignancies. This combination demonstrated promising activity, but at the expense of toxicity. Overall, 11/21 (52\%) of patients treated on the trial developed grade 3 to 4 toxicities including: hyperglycemia (14\%), hypophosphatemia (14\%), headache $(5 \%)$, hyperkalemia $(5 \%)$, hypokalemia $(5 \%)$, fatigue $(5 \%)$, elevated aspartate aminotransferase $(5 \%)$, decreased absolute neutrophil count/leukopenia (5\%), mucositis $(5 \%)$, anemia $(5 \%)$, infusion reaction $(5 \%)$, vomiting (5\%), and stomach leak/perforation (5\%). A total of five patients (24\%) experienced DLTs. Three of these patients $(14 \%)$ discontinued treatment before the first restaging due to DLTs (one patient with HNSCC; one patient with gastric cancer; and one patient with cervical adenocarcinoma). The most frequent grade 3 to 4 toxicities (observed in $\geq 10 \%$ of patients) were hyperglycemia and hypophosphatemia.

The most common non-hematologic adverse events (observed in $\geq 50 \%$ of patients) were dermatitis, fatigue, hypercholesterolemia, hyperglycemia, hypertriglyceridemia, elevated AST, mucositis, and proteinuria. Hyperglycemia and hyperlipidemia have been reported as common adverse events after temsirolimus treatment, affecting $17-26 \%$ and $6-27 \%$ treated patients respectively $[39,40]$. Seventy-one percent of our patients developed hyperglycemia and hypertriglyceridemia. Dermatitis occurs in $47-75 \%$ of patients treated with temsirolimus [39-41] and in $78 \%$ of patients treated with cetuximab [42]. We observed dermatitis in $57 \%$ of our patients, which is actually lower than the reported incidence for either single agent temsirolimus or cetuximab. Fatigue occurs in $71 \%$ of patients treated with temsirolimus [43] and in $63 \%$ of patients treated with cetuximab [44]. Fatigue was observed in $57 \%$ of our patients, which was lower than the reported incidence for single agent temsirolimus, but higher than that seen for single agent cetuximab. Mucositis was observed in 52\% of our patients, which is slightly higher than the $46 \%$ incidence rate reported in a phase 3 trial of single agent temsirolimus in renal cell carcinoma.[40] Proteinuria has been reported to occur in $32 \%$ of ovarian cancer patients treated with single agent bevacizumab. [45] Proteinuria was observed at a higher rate in our patients at $62 \%$.

The most common hematologic toxicity was anemia, which occurred in $19(90 \%)$ patients. We also observed neutropenia/leukopenia and thrombocytopenia in $7(33 \%)$ and $5(24 \%)$ treated patients, respectively. Grade 3/4 neutropenia and thrombocytopenia are rare with temsirolimus, cetuximab, or bevacizumab. In our treated patients, we observed only one patient with anemia and no patients with thrombocytopenia. None of our patients developed thromboembolic complications. In the current study, bevacizumab (10 mg/kg IV once every 14 days), temsirolimus (5 mg IV weekly), and cetuximab 100/75 $\mathrm{mg} / \mathrm{m}^{2}$ IV weekly) was determined to be the MTD. With the exception of bevacizumab, the other two drugs were dosed well below their label indication including, temsirolimus at $20 \%$ and cetuximab at $40 \%$ of the FDA approved doses. This reflects synergistic toxicity that 
could limit further development of this combination.

Evidence of clinical benefit in patients with HNSCC was observed. One of 9 HNSCC patients discontinued therapy after the first cetuximab infusion due to grade 3 infusion reaction. Of the remaining eight evaluable patients, seven patients made it to restaging and one patient was taken off therapy after cycle 1 due to clinical progression. This yielded an overall response rate of $25 \%(2 / 8)$ and a disease control rate of $38 \%(3 / 8)$. The median progression free survival (PFS) was 3 months in all eight evaluable patients with HNSCC and 1.8 months in all 21 patients on the trial. Anti-cancer activity has been observed with the combination of bevacizumab and cetuximab in HNSCC in both preclinical xenograft models and in a phase II study [22]. This phase II study yielded a comparable objective response rate of $16 \%$ but a higher disease control rate of $73 \%$. The median progression-free survival was 2.8 months; however, the patient population of that study was targeting locally advanced squamous cell carcinoma with only one line of prior therapy. This study also excluded patients treated with either prior cetuximab or bevacizumab. The toxicity profile in this phase II study was better compared to our study likely due to a less frequent dosing schedule. In addition, prolonged SD $\geq 6$ months was also observed in one of each patient with chondrosarcoma, melanoma, and adenocarcinoma of the tongue.

There are other clinical trials published in the literature that have combined three targeted agents [46-48]. For example, in a phase 1 trial, 34 patients with non-small cell lung cancer (NSCLC) received the combination of cetuximab, erlotinib and bevacizumab and were included in a subgroup analysis. [47] Unlike our trial, this combination was overall well-tolerated in these NSCLC patients. Of the NSCLC patients in this trial, the most common treatment-related grade $\geq 2$ adverse events were rash $(14 / 34,41 \%)$, hypomagnesemia $(9 / 34,27 \%)$, and fatigue $(5 / 34,15 \%)$. The antitumor activity in these NSCLC patients, however, is similar to our study with seven patients $(21 \%)$ achieving stable disease $(\mathrm{SD}) \geq 6$ months, two patients $(6 \%)$ achieving a partial response (PR) and two patients $(6 \%)$ achieving an unconfirmed partial response (uPR) (total $=11 / 34$, $(32 \%))$ in heavily pretreated patients. In another phase 1 trial, 32 patients with different types of solid tumors received the combination of everolimus, bevacizumab and panitumumab. [48] This trial was also overall well tolerated and appeared to have moderate clinical activity in refractory tumors. Common adverse events were skin rash/pruritus $(29 / 32,91 \%)$, mucositis/stomatitis (24/32, $75 \%$ ), hypomagnesemia $(23 / 32,72 \%)$, hypocalcemia $(18 / 32,56 \%)$ and hypokalemia $(16 / 32,50 \%)$. There were 3 partial responses; an additional 10 subjects had stable disease $\geq 6$ months. Three subjects with ovarian cancer and one with endometrial cancer achieved prolonged disease control ranging from 11 to $>40$ months.

Our study has several limitations. Firstly, a biomarker was not elucidated because molecular analysis could not be performed in many patients due to lack of tissue for testing. Secondly, the response signals may be limited because these patients were heavily pre-treated, with a median of three prior systemic therapies. Lastly, we were limited in total number of patients without prior exposure to single agent cetuximab, bevacizumab, or

\section{Baseline (1/16/13)}

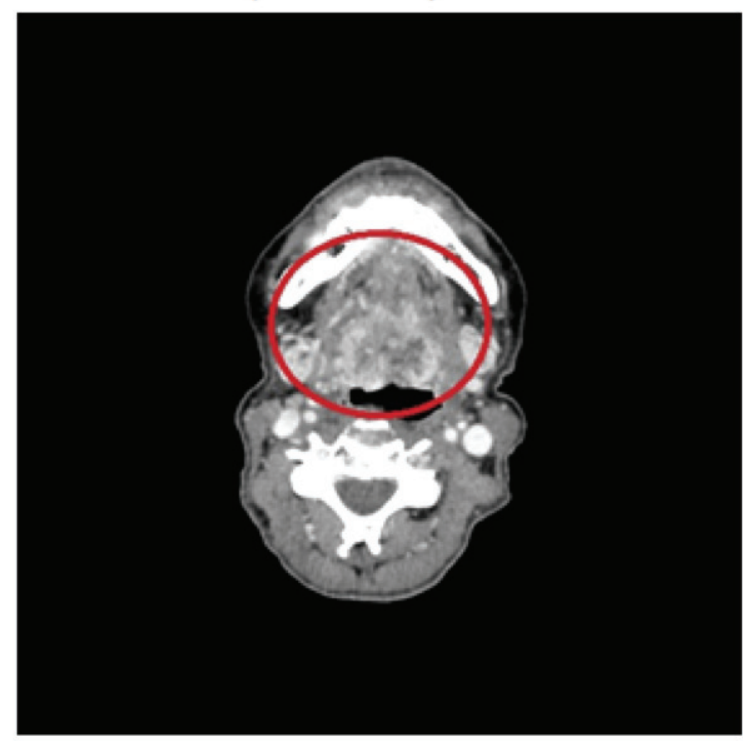

Cycle 2, day $22(3 / 14 / 13)$

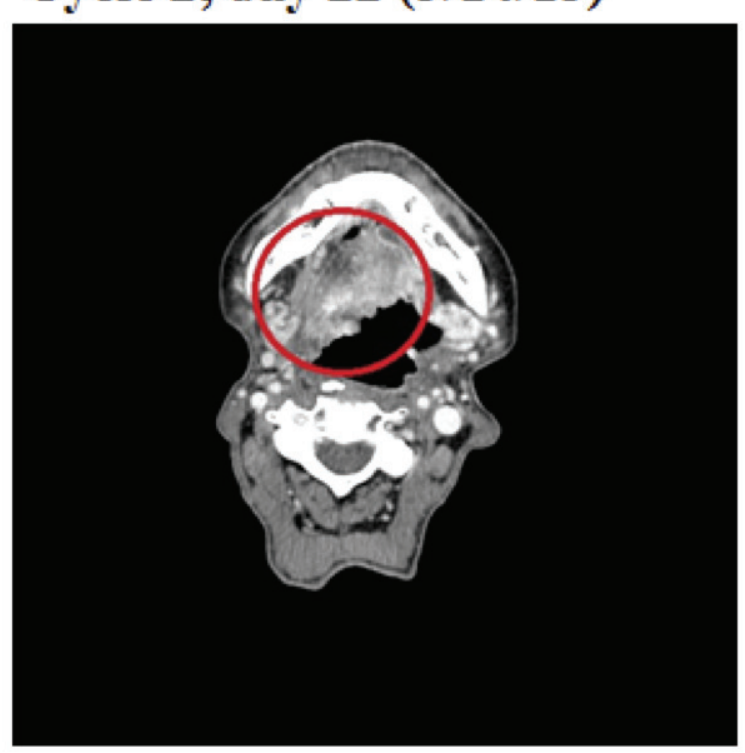

Figure 2: A patient with HNSCC showed partial response (-54\%) on the first restaging scan. The baseline and the first restaging $\mathrm{CT}$ scan of a 60 -year-old woman with squamous cell carcinoma of the base of the tongue who had received prior cetuximab. 
temsirolimus. The correlation between prior response to single agent and the efficacy of combination therapy could not be established.

In conclusion, the combination of bevacizumab, temsirolimus, and cetuximab showed activity in HNSCC; however, numerous toxicities were reported, which would require careful management during future clinical development.

\section{PATIENTS AND METHODS}

\section{Study design and dosing}

The experience with advanced malignancies reported was a single institution, phase I, open-label, dose-escalation study. This trial was open to all patients with advanced or metastatic cancer refractory to standard therapy, relapsed after standard therapy, or who had no standard therapy available that could improve survival by at least three months.

Treatment was administered on an outpatient basis at the University of Texas, MD Anderson Cancer Center (UTMDACC). A cycle of therapy was 28 days. No investigational, commercial agents or therapies other than those described here could be administered with the intent to treat the patient's malignancy. Bevacizumab was given on days 1 and 15 of each cycle, while temsirolimus and cetuximab was given weekly on days $1,8,15$, and 22 (Table 2). Restaging scans were performed after every two cycles. Consent was obtained and patients were treated in accordance with UTMDACC Institutional Review Board guidelines.

The protocol followed a standard $3+3$ design. If one patient in a cohort experienced a dose-limiting toxicity (DLT) during the first cycle, three additional patients were enrolled and treated at that dose level. If at any time more than $33 \%$ of patients in a cohort experienced a DLT, that cohort was closed to additional patients. Adverse events were graded based on the Common Terminology Criteria for Adverse Events, version 3.0 (CTCAEv3.0). DLTs were defined as any grade three or four non-hematologic toxicity that was believed to be related to any of the study medications (except nausea and vomiting responsive to appropriate regimens, correctable electrolyte imbalances or alopecia); any Grade 4 hematologic toxicity lasting 2 weeks or longer (as defined by the CTCAEv3.0) despite supportive care; any Grade 4 nausea or vomiting $>5$ days despite maximum anti-nausea regimens; any other Grade 3 non-hematologic toxicity including symptoms/signs of vascular leak or cytokine release syndrome; any severe or life-threatening complication/abnormality not defined in the CTCAEv3.0 that was attributable to the therapy. The MTD was defined by DLTs that occurred in the first cycle (four weeks). The use of growth factors was accepted during the clinical study.

\section{Eligibility criteria}

Key inclusion criteria were histologicallydocumented, advanced or metastatic solid tumors refractory to standard treatment or for which no standard therapy was available; Eastern Cooperative Oncology Group (ECOG) performance status $\leq$ two; absolute neutrophil count $\geq 1 \times 10^{9} / \mathrm{L}$; platelet count $\geq 50.0 \times$ $10^{9} / \mathrm{L}$; serum creatinine $<3.0 \mathrm{mg} / \mathrm{dL}$, aspartate transferase (AST), alanine transferase (ALT) $\leq$ five times the upper limit of normal (ULN); bilirubin $\leq 3.0 \mathrm{mg} / \mathrm{dL}$, total fasting cholesterol $\leq 350 \mathrm{mg} / \mathrm{dL}$; and triglyceride $\leq 400$ $\mathrm{mg} / \mathrm{dL}$. Key exclusion criteria were clinically significant, unexplained bleeding or hemoptysis within 28 days prior to study entry; poorly controlled hypertension (systolic blood pressure $>140 \mathrm{~mm} \mathrm{Hg}$, diastolic pressure $>90 \mathrm{~mm}$ $\mathrm{Hg}$ on medication); patients with clinically significant cardiovascular disease; KRAS mutated colorectal cancer patients; history of hypersensitivity to any of the three drugs; patients who had major surgery within 6 weeks of enrollment in the study; and pregnancy. Patients with prior exposure to bevacizumab, cetuximab or mTOR inhibitors were not excluded from the study, nor were patients with a history of venous thromboembolism excluded.

\section{Assessment of tumor response}

Tumor measurements were performed on patients with measurable disease at baseline and every two cycles thereafter. Measurable target lesions were evaluated for response using Response Evaluation Criteria in Solid Tumors (RECIST 1.0) [49, 50]. For the purpose of this report, prolonged stable disease (SD) was defined as lasting $\geq 6$ months.

\section{Molecular analysis (PIK3CA, PTEN, RAF and $R A S)$}

PIK3CA, RAF, RAS mutations were investigated in archival formalin-fixed, paraffin-embedded tissue blocks. DNA was extracted from microdissected paraffin-embedded tumor sections and analyzed using a polymerase chain reaction (PCR)-based DNA sequencing method for PIK3CA mutations in codons [c]532-554 of exon 9 (helical domain) and c1011-1062 of exon 20 (kinase domain) [51], which included the mutation hot spot region of the PIK3CA proto-oncogene by Sanger sequencing following amplification of $276 \mathrm{bp}$ and 198 bp amplicons, respectively. Codons 12, 13, and 61 were examined for $K R A S$ and $N R A S$ mutations and for $B R A F$, codons 468-474, codons 595-600, and mutations of exon 15 by pyro-sequencing were examined as previously 
described [52]. PTEN mutations were detected in exons 1-9 using PCR-based DNA sequencing and the lower limit of detection was approximately $20 \%$ [53]. PTEN loss by immunohistochemistry (IHC) generally indicates aberrant or mutated PTEN, which serves to activate the PI3 kinase/ AKT/mTOR pathway $[54,55]$. Formalin-fixed paraffinembedded sections ( $5 \mu \mathrm{m}$ thick) from biopsy or resection specimens were used for IHC analysis. The sections were stained with antibody to PTEN (Dako, Carpinteria, CA). All histology was centrally reviewed and all testing was performed in the Clinical Laboratory Improvement Amendment (CLIA) -certified Molecular Diagnostic Laboratory (MDL) at UTMDACC.

\section{CONFLICTS OF INTEREST}

The authors do not have any conflicts of interest.

\section{REFERENCES}

1. Park SR, Davis M, Doroshow JH and Kummar S. Safety and feasibility of targeted agent combinations in solid tumours. Nature reviews Clinical oncology. 2013; 10:154168.

2. Prewett M, Rothman M, Waksal H, Feldman M, Bander $\mathrm{NH}$ and Hicklin DJ. Mouse-human chimeric anti-epidermal growth factor receptor antibody $\mathrm{C} 225$ inhibits the growth of human renal cell carcinoma xenografts in nude mice. Clinical Cancer Research. 1998; 4:2957-2966.

3. Institute NC. FDA Approval for Cetuximab. 2014.

4. Rowe DH, Huang J, Kayton ML, Thompson R, Troxel A, O'Toole KM, Yamashiro D, Stolar CJ and Kandel JJ. Anti-VEGF antibody suppresses primary tumor growth and metastasis in an experimental model of Wilms' tumor. Journal of pediatric surgery. 2000; 35:30-32; discussion 3233.

5. Carmeliet P. VEGF as a key mediator of angiogenesis in cancer. Oncology. 2005; 69 Suppl 3:4-10.

6. Ferrara N. VEGF as a therapeutic target in cancer. Oncology. 2005; 69 Suppl 3:11-16.

7. Ferrara N, Hillan KJ and Novotny W. Bevacizumab (Avastin), a humanized anti-VEGF monoclonal antibody for cancer therapy. Biochemical and biophysical research communications. 2005; 333:328-335.

8. Ferrara N and Kerbel RS. Angiogenesis as a therapeutic target. Nature. 2005; 438:967-974.

9. National Cancer Institute. (2014). FDA Approval for Bevacizumab.

10. Simpson D and Curran MP. Temsirolimus: in advanced renal cell carcinoma. Drugs. 2008; 68:631-638.

11. Hidalgo $\mathrm{M}$ and Rowinsky EK. The rapamycin-sensitive signal transduction pathway as a target for cancer therapy. Oncogene. 2000; 19:6680-6686.

12. Kwitkowski VE, Prowell TM, Ibrahim A, Farrell AT,
Justice R, Mitchell SS, Sridhara R and Pazdur R. FDA approval summary: temsirolimus as treatment for advanced renal cell carcinoma. The oncologist. 2010; 15:428-435.

13. Adjei AA and Hidalgo M. Intracellular signal transduction pathway proteins as targets for cancer therapy. J Clin Oncol. 2005; 23:5386-5403.

14. Baselga $\mathrm{J}$ and Arteaga CL. Critical update and emerging trends in epidermal growth factor receptor targeting in cancer. J Clin Oncol. 2005; 23:2445-2459.

15. Herbst RS, Johnson DH, Mininberg E, Carbone DP, Henderson T, Kim ES, Blumenschein G, Lee JJ, Liu DD, Truong MT, Hong WK, Tran H, Tsao A, Xie D, Ramies DA, Mass R, et al. Phase I/II Trial Evaluating the AntiVascular Endothelial Growth Factor Monoclonal Antibody Bevacizumab in Combination With the HER-1/Epidermal Growth Factor Receptor Tyrosine Kinase Inhibitor Erlotinib for Patients With Recurrent Non-Small-Cell Lung Cancer. Journal of Clinical Oncology. 2005; 23:2544-2555.

16. Larsen AK, Ouaret D, El Ouadrani K and Petitprez A. Targeting EGFR and VEGF(R) pathway cross-talk in tumor survival and angiogenesis. Pharmacol Ther. 131:80-90.

17. Tabernero J. The role of VEGF and EGFR inhibition: implications for combining anti-VEGF and anti-EGFR agents. Mol Cancer Res. 2007; 5:203-220.

18. Poindessous V, Ouaret D, El Ouadrani K, Battistella A, Megalophonos VF, Kamsu-Kom N, Petitprez A, Escargueil AE, Boudou P, Dumont S, Cervera P, Flejou JF, Andre T, Tournigand C, Chibaudel B, de Gramont A, et al. EGFR- and VEGF(R)-targeted small molecules show synergistic activity in colorectal cancer models refractory to combinations of monoclonal antibodies. Clin Cancer Res. 2011; 17:6522-6530.

19. Martinelli E, Troiani T, Morgillo F, Rodolico G, Vitagliano D, Morelli MP, Tuccillo C, Vecchione L, Capasso A, Orditura M, De Vita F, Eckhardt SG, Santoro M, Berrino L and Ciardiello F. Synergistic antitumor activity of sorafenib in combination with epidermal growth factor receptor inhibitors in colorectal and lung cancer cells. Clin Cancer Res. 2010; 16:4990-5001.

20. Ciardiello F, Bianco R, Damiano V, Fontanini G, Caputo R, Pomatico G, De Placido S, Bianco AR, Mendelsohn J and Tortora G. Antiangiogenic and antitumor activity of anti-epidermal growth factor receptor C225 monoclonal antibody in combination with vascular endothelial growth factor antisense oligonucleotide in human GEO colon cancer cells. Clin Cancer Res. 2000; 6:3739-3747.

21. Piha-Paul SA, Wheler JJ, Fu S, Levenback C, Lu K, Falchook GS, Naing A, Hong DS, Tsimberidou AM and Kurzrock R. Advanced gynecologic malignancies treated with a combination of the VEGF inhibitor bevacizumab and the mTOR inhibitor temsirolimus. Oncotarget. 2014; 5:1846-1855. doi: 10.18632/oncotarget.1834.

22. Argiris A, Kotsakis AP, Hoang T, Worden FP, Savvides P, Gibson MK, Gyanchandani R, Blumenschein GR, Jr., Chen HX, Grandis JR, Harari PM, Kies MS and Kim S. 
Cetuximab and bevacizumab: preclinical data and phase II trial in recurrent or metastatic squamous cell carcinoma of the head and neck. Annals of oncology. 2013; 24:220-225.

23. Blagosklonny MV. Hypoxia-inducible factor: Achilles' heel of antiangiogenic cancer therapy (review). International journal of oncology. 2001; 19:257-262.

24. Blagosklonny MV. Antiangiogenic therapy and tumor progression. Cancer cell. 2004; 5:13-17.

25. Choi KS, Bae MK, Jeong JW, Moon HE and Kim KW. Hypoxia-induced angiogenesis during carcinogenesis. Journal of biochemistry and molecular biology. 2003; 36:120-127.

26. Hicklin DJ and Ellis LM. Role of the vascular endothelial growth factor pathway in tumor growth and angiogenesis. J Clin Oncol. 2005; 23:1011-1027.

27. Lee JW, Bae SH, Jeong JW, Kim SH and Kim KW. Hypoxia-inducible factor (HIF-1)alpha: its protein stability and biological functions. Experimental and molecular medicine. 2004; 36:1-12.

28. Tsuzuki Y, Fukumura D, Oosthuyse B, Koike C, Carmeliet $\mathrm{P}$ and Jain RK. Vascular endothelial growth factor (VEGF) modulation by targeting hypoxia-inducible factor-1alpha--> hypoxia response element--> VEGF cascade differentially regulates vascular response and growth rate in tumors. Cancer Res. 2000; 60:6248-6252.

29. Yu JL, Rak JW, Coomber BL, Hicklin DJ and Kerbel RS. Effect of p53 status on tumor response to antiangiogenic therapy. Science. 2002; 295:1526-1528.

30. Zhong H, De Marzo AM, Laughner E, Lim M, Hilton DA, Zagzag D, Buechler P, Isaacs WB, Semenza GL and Simons JW. Overexpression of hypoxia-inducible factor 1alpha in common human cancers and their metastases. Cancer Res. 1999; 59:5830-5835.

31. Escuin D, Simons JW and Giannakakou P. Exploitation of the HIF axis for cancer therapy. Cancer Biol Ther. 2004; 3:608-611.

32. Powis G and Kirkpatrick L. Hypoxia inducible factor1alpha as a cancer drug target. Molecular cancer therapeutics. 2004; 3:647-654.

33. Welsh SJ, Koh MY and Powis G. The hypoxic inducible stress response as a target for cancer drug discovery. Semin Oncol. 2006; 33:486-497.

34. Welsh SJ and Powis G. Hypoxia inducible factor as a cancer drug target. Current cancer drug targets. 2003; 3:391-405.

35. Wang H-W, Yang S-H, Huang G-D, Lin J-K, Chen W-S, Jiang J-K, Lan Y-T, Lin C-C, Hwang W-L, Tzeng C-H, Li $\mathrm{A}-\mathrm{Y}$, Yen $\mathrm{C}-\mathrm{C}$ and Teng $\mathrm{H}-\mathrm{W}$. Temsirolimus enhances the efficacy of cetuximab in colon cancer through a CIP2Adependent mechanism. Journal of Cancer Research and Clinical Oncology. 2014; 140:561-571.

36. Seiwert TY, Adkins D, Worden F, Wade JL, Hu S, Price K, Zavala J, Lussier Y, Vokes EE and Cohen EEW. Activity of Temsirolimus Added to Cetuximab in Patients With Cetuximab-Resistant, Recurrent/Metastatic Head-and-
Neck Cancer: Results of the Randomized Phase 2 MaestroHN Study. International Journal of Radiation Oncology • Biology • Physics. 88:510.

37. Said R, Hong DS, Warneke CL, Lee JJ, Wheler JJ, Janku F, Naing A, Falchook GS, Fu S, Piha-Paul S, Tsimberidou AM and Kurzrock R. P53 mutations in advanced cancers: clinical characteristics, outcomes, and correlation between progression-free survival and bevacizumab-containing therapy. Oncotarget. 2013; 4:705-714. doi: 10.18632/ oncotarget. 974.

38. Schwaederle M, Lazar V, Validire P, Hansson J, Lacroix L, Soria JC, Pawitan Y and Kurzrock R. VEGF-A Expression Correlates with TP53 Mutations in Non-Small Cell Lung Cancer: Implications for Antiangiogenesis Therapy. Cancer Res. 2015; 75:1187-1190.

39. Atkins MB, Hidalgo M, Stadler WM, Logan TF, Dutcher JP, Hudes GR, Park Y, Liou SH, Marshall B, Boni JP, Dukart G and Sherman ML. Randomized phase II study of multiple dose levels of CCI-779, a novel mammalian target of rapamycin kinase inhibitor, in patients with advanced refractory renal cell carcinoma. J Clin Oncol. 2004; 22:909918.

40. Hudes G, Carducci M, Tomczak P, Dutcher J, Figlin R, Kapoor A, Staroslawska E, Sosman J, McDermott D, Bodrogi I, Kovacevic Z, Lesovoy V, Schmidt-Wolf IG, Barbarash O, Gokmen E, O'Toole T, et al. Temsirolimus, interferon alfa, or both for advanced renal-cell carcinoma. The New England journal of medicine. 2007; 356:22712281.

41. Raymond E, Alexandre J, Faivre S, Vera K, Materman E, Boni J, Leister C, Korth-Bradley J, Hanauske A and Armand JP. Safety and pharmacokinetics of escalated doses of weekly intravenous infusion of CCI-779, a novel mTOR inhibitor, in patients with cancer. J Clin Oncol. 2004; 22:2336-2347.

42. Maubec E, Petrow P, Scheer-Senyarich I, Duvillard P, Lacroix L, Gelly J, Certain A, Duval X, Crickx B, Buffard V, Basset-Seguin N, Saez P, Duval-Modeste AB, Adamski H, Mansard S, Grange F, et al. Phase II study of cetuximab as first-line single-drug therapy in patients with unresectable squamous cell carcinoma of the skin. J Clin Oncol. 2011; 29:3419-3426.

43. Kruczek K, Ratterman M, Tolzien K, Sulo S, Lestingi TM and Nabhan C. A phase II study evaluating the toxicity and efficacy of single-agent temsirolimus in chemotherapynaive castration-resistant prostate cancer. British journal of cancer. 2013; 109:1711-1716.

44. Chan JA, Blaszkowsky LS, Enzinger PC, Ryan DP, Abrams TA, Zhu AX, Temel JS, Schrag D, Bhargava P, Meyerhardt JA, Wolpin BM, Fidias P, Zheng H, Florio $\mathrm{S}$, Regan $\mathrm{E}$ and Fuchs CS. A multicenter phase II trial of single-agent cetuximab in advanced esophageal and gastric adenocarcinoma. Annals of oncology. 2011; 22(6):13671373 . 
45. Burger RA, Sill MW, Monk BJ, Greer BE and Sorosky JI. Phase II trial of bevacizumab in persistent or recurrent epithelial ovarian cancer or primary peritoneal cancer: a Gynecologic Oncology Group Study. J Clin Oncol. 2007; 25:5165-5171.

46. Lin CC, Calvo E, Papadopoulos KP, Patnaik A, Sarantopoulos J, Mita AC, Preston GG, Mita MM, Rodon J, Mays T, Yeh IT, O'Rourke P, Takimoto CH, Dancey JE, Chen $\mathrm{H}$ and Tolcher AW. Phase I study of cetuximab, erlotinib, and bevacizumab in patients with advanced solid tumors. Cancer Chemother Pharmacol. 2009; 63:10651071.

47. Falchook GS, Naing A, Hong DS, Zinner R, Fu S, Piha-Paul SA, Tsimberidou AM, Morgan-Linnell SK, Jiang Y, Bastida C, Wheler JJ and Kurzrock R. Dual EGFR inhibition in combination with anti-VEGF treatment: a phase I clinical trial in non-small cell lung cancer. Oncotarget. 2013; 4:118127. doi: 10.18632/oncotarget.763.

48. Vlahovic G, Meadows KL, Uronis HE, Morse MA, Blobe GC, Riedel RF, Zafar SY, Alvarez-Secord A, Gockerman J, Starodub AN, Ready NE, Anderson EL, Bendell JC and Hurwitz HI. A phase I study of bevacizumab, everolimus and panitumumab in advanced solid tumors. Cancer chemotherapy and pharmacology. 2012; 70:95-102.

49. Eisenhauer EA, Therasse P, Bogaerts J, Schwartz LH, Sargent D, Ford R, Dancey J, Arbuck S, Gwyther S, Mooney M, Rubinstein L, Shankar L, Dodd L, Kaplan R, Lacombe D and Verweij J. New response evaluation criteria in solid tumours: revised RECIST guideline (version 1.1). European journal of cancer. 2009; 45:228-247.

50. Benjamin RS, Choi H, Macapinlac HA, Burgess MA, Patel
SR, Chen LL, Podoloff DA and Charnsangavej C. We should desist using RECIST, at least in GIST. J Clin Oncol. 2007; 25:1760-1764.

51. Samuels Y, Wang Z, Bardelli A, Silliman N, Ptak J, Szabo S, Yan H, Gazdar A, Powell SM, Riggins GJ, Willson JK, Markowitz S, Kinzler KW, Vogelstein B and Velculescu VE. High frequency of mutations of the PIK3CA gene in human cancers. Science. 2004; 304:554.

52. Zuo Z, Chen SS, Chandra PK, Galbincea JM, Soape M, Doan S, Barkoh BA, Koeppen H, Medeiros LJ and Luthra R. Application of COLD-PCR for improved detection of KRAS mutations in clinical samples. Modern pathology. 2009; 22:1023-1031.

53. Janku F, Hong DS, Fu S, Piha-Paul SA, Naing A, Falchook GS, Tsimberidou AM, Stepanek VM, Moulder SL, Lee JJ, Luthra R, Zinner RG, Broaddus RR, Wheler JJ and Kurzrock R. Assessing PIK3CA and PTEN in early-phase trials with $\mathrm{PI} 3 \mathrm{~K} / \mathrm{AKT} / \mathrm{mTOR}$ inhibitors. Cell reports. 2014; 6:377-387.

54. Chow LM and Baker SJ. PTEN function in normal and neoplastic growth. Cancer letters. 2006; 241:184-196.

55. Lotan TL, Gurel B, Sutcliffe S, Esopi D, Liu W, Xu J, Hicks JL, Park BH, Humphreys E, Partin AW, Han M, Netto GJ, Isaacs WB and De Marzo AM. PTEN protein loss by immunostaining: analytic validation and prognostic indicator for a high risk surgical cohort of prostate cancer patients. Clin Cancer Res. 2011; 17:6563-6573. 